Research article

\title{
Long-term vitamin E supplementation fails to reduce lipid peroxidation in people at cardiovascular risk: analysis of underlying factors

\author{
Chiara Chiabrando*1, Fausto Avanzini ${ }^{2}$, Claudia Rivalta1 ${ }^{1}$, Fabio Colombo ${ }^{2}$, \\ Roberto Fanelli ${ }^{1}$, Gaetana Palumbo ${ }^{3}$ and Maria Carla Roncaglioni ${ }^{2}$ for PPP \\ Collaborative Group on the antioxidant effect of vitamin $\mathrm{E}$
}

Address: ${ }^{1}$ Department of Environmental Health Sciences, Istituto di Ricerche Farmacologiche 'Mario Negri', via Eritrea 62, 20157 Milano, Italy, ${ }^{2}$ Department of Cardiovascular Research, Istituto di Ricerche Farmacologiche 'Mario Negri', via Eritrea 62, 20157 Milano, Italy and ${ }^{3}$ Divisione di Medicina V piano, Azienda Ospedaliera Ospedale San Carlo Borromeo, Via Pio II 3, 20153 Milano, Italy

E-mail: Chiara Chiabrando* - chiabrando@marionegri.it; Fausto Avanzini - avanzini@marionegri.it; Claudia Rivalta - rivalta@marionegri.it; Fabio Colombo - fabio@marionegri.it; Roberto Fanelli - fanelli@marionegri.it; Gaetana Palumbo - geetana.palumbo@tiscalinet.it; Maria Roncaglioni - roncaglioni@marionegri.it

${ }^{*}$ Corresponding author

Published: 19 March 2002

Current Controlled Trials in Cardiovascular Medicine 2002, 3:5

This article is available from: http://crm.controlled-trials.com/content/3/1/5
Received: 15 January 2002

Accepted: 19 March 2002

(c) 2002 Chiabrando et al; licensee BioMed Central Ltd. Verbatim copying and redistribution of this article are permitted in any medium for any purpose, provided this notice is preserved along with the article's original URL.

Keywords: Vitamin E, cardiovascular prevention, lipid peroxidation, F2-isoprostane, hypertension

\begin{abstract}
Background: Antioxidant supplementation with vitamin $E$ had no effect in the prevention of cardiovascular diseases (CVD) in three recent large, randomized clinical trials. In order to reassess critically the role of vitamin E in CVD prevention, it is important to establish whether these results are related to a lack of antioxidant action.
\end{abstract}

Methods: We examined the in vivo antioxidant effect of vitamin E $(300 \mathrm{mg} /$ day for about three years) in 144 participants in the Primary Prevention Project (females and males, aged $\geq 50 \mathrm{y}$, with at least one major CV risk factor, but no history of CVD). Urinary 8-epi-PGF $2 \alpha$ (isoprostane $F_{2 \alpha^{-}}$ III or $15-\mathrm{F}_{2 \mathrm{t}}$-isoP), a validated biomarker of lipid peroxidation, was measured by mass spectrometry.

Results: Urinary excretion of 8-epi-PGF $2 \alpha$ [pg/mg creatinine, median (range)] was 141 (67-498) in treated and $148(76-56 I)$ in untreated subjects $(p=0.10)$. Taking into account possible confounding variables, multiple regression analysis confirmed that vitamin $E$ had no significant effect on this biomarker. Levels of 8-epi-PGF $2 \alpha$ were in the normal range for most subjects, except smokers and those with uncontrolled blood pressure or hyperglycemia.

Conclusions: Prolonged vitamin E supplementation did not reduce lipid peroxidation in subjects with major cardiovascular risk factors. The observation that the rate of lipid peroxidation was near normal in a large proportion of subjects may help explain why vitamin $E$ was not effective as an antioxidant in the PPP study and was ineffective for CVD prevention in large scale trials. 


\section{Background}

The "oxidative hypothesis" of atherosclerosis proposes that oxidative modification of lipids in low-density lipoproteins (LDL) contributes to atherogenesis $[1,2]$. Antioxidants that are effective against lipid peroxidation should therefore reduce atherosclerosis and hence afford protection from cardiovascular diseases (CVD)[1]. In contrast to a) epidemiological evidence that antioxidants taken with the diet or as supplements reduce cardiovascular (CV) risk [3], and b) experimental data supporting its anti-atherogenic properties [4], vitamin E failed to show any beneficial effect in recent large intervention studies [5]. In two large-scale trials, long-term supplementation with vitamin E (300-400 lU/day) failed to reduce cardiovascular events in post-myocardial infarction patients (GISSI-Prevenzione [6]) and in subjects at high CV risk (HOPE [7]). In the trial conducted by our group (Primary Prevention Project, PPP [8]), vitamin E (300 mg/day) taken over three years also showed no effect on the incidence of cardiovascular events in individuals with one or more major risk factors (see Methods). Therefore, the question whether vitamin $\mathrm{E}$ had an effective in vivo antioxidant action in the populations under study in these trials is under debate [9-12].

When these studies were designed, the antioxidant efficacy of vitamin $\mathrm{E}$ in humans had not been demonstrated in vivo because of the lack of reliable methods [13]. Measurement of urinary or circulating F2-isoprostanes $\left(\mathrm{iPF}_{2}\right.$ or $\mathrm{F}_{2^{-}}$ isoP) is now accepted as a reliable tool for evaluating the rate of lipid peroxidation in vivo[9,14-16]. Using urinary excretion of 8-epi-PGF $2 \alpha$ (also termed $\mathrm{PPF}_{2 \alpha}$-III or $15-\mathrm{F}_{2 \mathrm{t}^{-}}$ isoP) as a biomarker, it has been shown that short-term administration of vitamin E (600 mg/day for 14 days) reduced in vivo lipid peroxidation in some clinical settings where oxidative stress is abnormally high, e.g., diabetes mellitus (-37\%), hypercholesterolemia $(-58 \%)$ and cystic fibrosis $(-42 \%)$ [17-19]. In contrast, vitamin $\mathrm{E}$ had no antioxidant activity in conditions where lipid peroxidation was normal [20]. No data are available on the antioxidant effect of longer-term supplementation with vitamin $\mathrm{E}$ in subjects at moderate/high cardiovascular risk.

Using a highly selective and validated mass spectrometric assay for 8-epi-PGF $2 \alpha[21]$, we measured in vivo lipid peroxidation in PPP trial participants who had taken vitamin E daily for about three years $v s$ those who did not take vitamin E.

\section{Methods}

PPP is a large, randomized, controlled $2 \times 2$ factorial trial on primary prevention of CVD [8]. It was designed to test the efficacy of long-term administration of vitamin E (synthetic $\alpha$-tocopherol, $300 \mathrm{mg} /$ day) and/or aspirin (100
Table I: Major cardiovascular risk factors in the 144 subjects.

\begin{tabular}{lc}
\hline RISK FACTOR* & $\mathrm{n}(\%)$ \\
\hline & \\
Old age $\geq 65$ y & $38(26)$ \\
Male sex & $63(44)$ \\
Smoking & $24(17)$ \\
Hypertension & $136(94)$ \\
Diabetes & $12(8)$ \\
Hypercholesterolemia & $43(30)$ \\
Obesity & $32(22)$ \\
Family history of premature myocardial & $17(12)$ \\
infraction & \\
& \\
\hline
\end{tabular}

*See Methods for definition

$\mathrm{mg} /$ day) in preventing cardiovascular events in subjects of both sexes aged $\geq 50$ years, with at least one of the following cardiovascular risk factors: old age ( $\geq 65 \mathrm{yr}$ ); hypertension (systolic blood pressure $\geq 160 \mathrm{~mm} \mathrm{Hg}$ or diastolic blood pressure $\geq 95 \mathrm{~mm} \mathrm{Hg}$ on at least three separate occasions); hypercholesterolemia ( $\geq 250 \mathrm{mg} / \mathrm{dL}$ on at least two separate occasions); diabetes mellitus $(\geq 140 \mathrm{mg} / \mathrm{dL}$ fasting venous plasma glucose, on at least two separate occasions); chronic drug treatment for any of the three latter conditions; obesity (body mass index $\geq 30 \mathrm{~kg} / \mathrm{m}^{2}$ ); and premature myocardial infarction before 55 years of age in at least one parent or sibling. Patients with a history of cardiovascular events or diseases were not included. Table 1 shows the frequency of these CV risk factors in our sample.

Overnight urine was obtained from subjects consecutively presenting at five participating centers for a scheduled follow-up visit after at least one year of randomized treatment. With a sample size of 70 individuals per arm, the study had a $90 \%$ power $(1-\beta)$ to detect, with $\alpha=0.05$, a difference of at least $25 \%$ in urinary 8 -epi-PGF $2 \alpha$ between treated and untreated individuals. Two groups of 72 subjects treated or not treated with vitamin E were studied. Clinical and biochemical variables were reassessed yearly and on the occasion of urine collection.

Urinary 8-epi-PGF $2 \alpha$ was selectively measured as we have described previously [21] using immunoaffinity chromatography for selective extraction/purification and a stable isotope dilution assay with gas chromatography-negative ion chemical ionization mass spectrometry for quantitation, with ${ }^{2} \mathrm{H}_{4}-8-e p i-\mathrm{PGF}_{2 \alpha}$ as the internal standard. Urinary excretion of 8 -epi-PGF $2 \alpha$ was expressed as $\mathrm{pg} / \mathrm{mg}$ creatinine. Creatinine was measured highly selectively by stable-isotope dilution HPLC-electrospray-tandem mass spectrometry, using ${ }^{2} \mathrm{H}_{3}$-creatinine as the internal stand- 
Table 2: Baseline characteristics of the two study groups

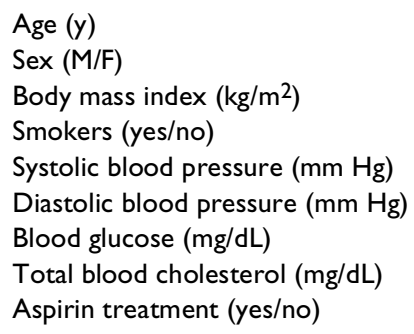

$$
\begin{gathered}
59 \pm 6 \\
32 / 40 \\
27 \pm 4 \\
15 / 57 \\
146 \pm 16 \\
88 \pm 8 \\
91 \pm 32 \\
243 \pm 47 \\
36 / 36
\end{gathered}
$$

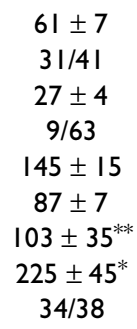

Values are expressed as mean $\pm S D$ or number. ${ }^{*} \mathrm{p}<0.05,{ }^{* *} \mathrm{p}<0.0 \mathrm{I}$

ard. Urine was stored at $-20^{\circ} \mathrm{C}$ until analyzed. Analyses were done on blind-coded samples.

Means were compared by the non-parametric MannWhitney $\mathrm{U}$ test to avoid assumptions about the distribution of the variables. Levels of 8 -epi-PGF $2 \alpha$ were expressed as median (range) values. Multiple regression analysis was used to 1) evaluate the effect of vitamin E on urinary excretion of 8-epi-PGF $2 \alpha^{\prime}$ taking into account the following potential confounding variables (age, sex, aspirin treatment, smoking, systolic and diastolic blood pressure, blood glucose, blood cholesterol and obesity), and 2) assess whether any of these variables was independently associated with lipid peroxidation. Linear correlation analysis was also used. Probability values of $\mathrm{p} \leq 0.05$ (two tails) were considered to be statistically significant.

\section{Results}

\section{Antioxidant Effect of Vitamin E}

In vivo lipid peroxidation was not reduced significantly by vitamin $\mathrm{E}$ (Figure 1), as indicated by the similar urinary excretion of 8 -epi-PGF $2 \alpha$ in the supplemented group and in the controls [141 (67-498) vs 148 (76-561) pg/mg creatinine, $\mathrm{p}=0.10]$. These subjects had mean $\pm \mathrm{SD}$ followup durations of $2.8 \pm 1.0$ and $2.7 \pm 1.1$ years, respectively. Baseline characteristics were well balanced across the two study groups, except for a slight difference in blood levels of glucose and cholesterol (Table 2). For this reason, we excluded with reasonable confidence a potential bias due to different baseline levels of urinary 8-epi-PGF $2 \alpha$. Multiple regression analysis, which takes into account possible confounding variables at the time of urine collection (age, sex, smoking, blood glucose, blood cholesterol, systolic and diastolic blood pressure, body mass index, aspirin treatment), confirmed that vitamin $\mathrm{E}$ had no significant overall effect on urinary 8-epi-PGF $2 \alpha(\beta=-0.14, \mathrm{p}=0.12$, Table 3).

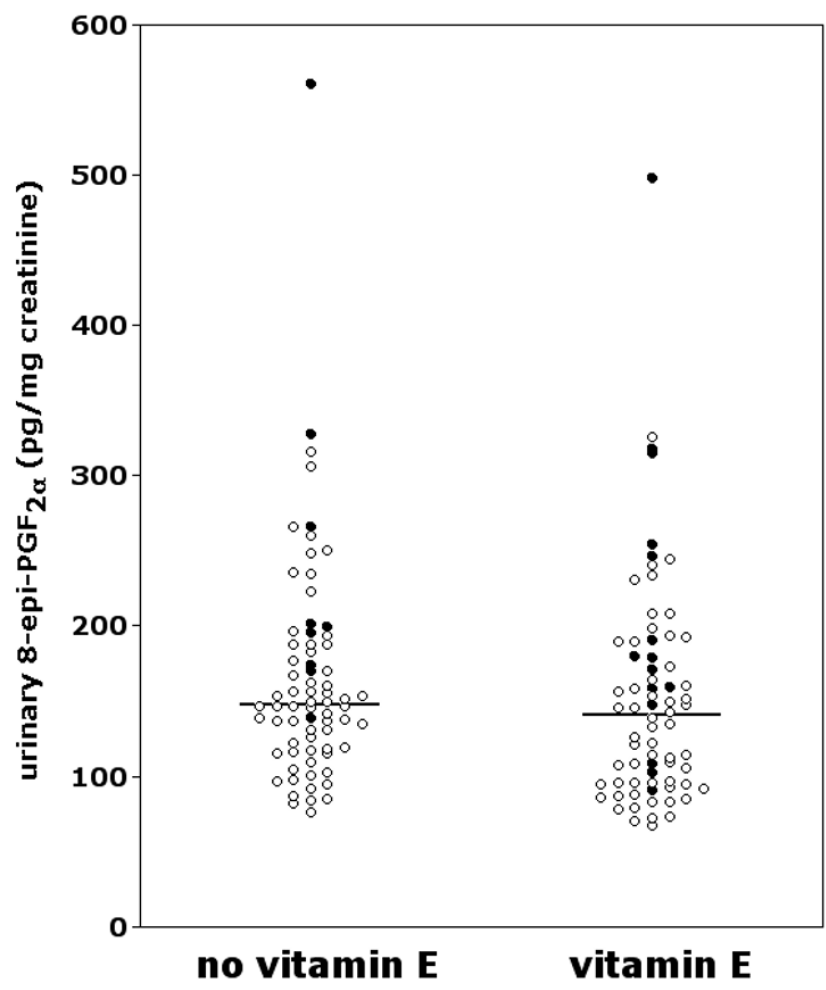

Figure I

Urinary excretion of 8-epi-PGF $2 \alpha$ in PPP participants supplemented or not with vitamin E. Smokers are indicated by filled circles. The horizontal lines represent the median.

Smoking was the only strong determinant of lipid peroxidation in the overall sample (Table 3, discussed below). Since it is known that vitamin $\mathrm{E}$ does not reduce excessive lipid peroxidation in smokers $[22,23]$, we investigated whether the presence of smokers in our sample might mask an antioxidant effect of vitamin $\mathrm{E}$ in the nonsmokers $(\mathrm{n}=120 ; 63$ untreated, 57 treated with vitamin $\mathrm{E})$. The 
Table 3: Multiple regression analysis: variables associated with urinary excretion of 8-epi-PGF $2 \alpha$

\begin{tabular}{|c|c|c|c|c|}
\hline \multirow[b]{2}{*}{ VARIABLE } & \multicolumn{2}{|c|}{ all subjects $(n=144)$} & \multicolumn{2}{|c|}{ nonsmokers $(n=120)$} \\
\hline & $\beta$ & $\mathrm{P}$ & $\beta$ & $P$ \\
\hline Smoking & 0.46 & $<0.0001$ & - & - \\
\hline Vitamin E treatment & -0.14 & 0.12 & -0.10 & 0.32 \\
\hline Systolic blood pressure $(\mathrm{mmHg})$ & 0.13 & 0.19 & 0.26 & 0.02 \\
\hline Obesity & 0.12 & 0.21 & 0.15 & 0.15 \\
\hline $\operatorname{Sex}(M)$ & 0.11 & 0.22 & 0.13 & 0.21 \\
\hline Aspirin treatment & -0.10 & 0.24 & -0.07 & 0.45 \\
\hline Blood glucose (mg/dL) & 0.09 & 0.35 & 0.17 & 0.11 \\
\hline Diastolic blood pressure $(\mathrm{mmHg})$ & -0.05 & 0.63 & -0.07 & 0.50 \\
\hline Age $(y)$ & 0.04 & 0.67 & 0.09 & 0.38 \\
\hline Blood cholesterol (mg/dL) & 0.03 & 0.74 & 0.11 & 0.30 \\
\hline
\end{tabular}

levels of 8-epi-PGF $2 \alpha$ in nonsmokers, however, were not significantly reduced by prolonged vitamin E supplementation [122 (67-326) vs $146(76-316), \mathrm{p}=0.09)]$. Multivariate analysis confirmed that vitamin $\mathrm{E}$ did not reduce lipid peroxidation in this sample $(\beta=-0.10, \mathrm{p}=0.32$, Table 3).

\section{Lipid Peroxidation in Subjects at CV Risk}

Since vitamin $\mathrm{E}$ has thus far proved effective as an in vivo antioxidant in humans when lipid peroxidation is excessive $[17-19,24]$, but not when it is normal [20], we addressed the question whether in subjects eligible for primary prevention of CVD, lipid peroxidation was increased enough to decrease appreciably with vitamin $\mathrm{E}$. As a whole, this sample of patients with at least one CVD risk factor did not have an abnormal rate of lipid peroxidation. The levels of urinary 8-epi-PGF $2 \alpha$ in untreated nonsmokers [146 (76-316) pg/mg creatinine] were similar to those of controls in other studies where this biomarker was selectively measured by mass spectrometry $[20,22]$. They were also similar to those we found in healthy nonsmoking volunteers [139 (71-256) pg/mg creatinine; mean $\pm S D$ age, $37 \pm 11 \mathrm{y} ; \mathrm{n}=20$, unpublished data].

To better characterize the level of CV risk in our sample, we calculated a global CV risk score for each subject. We used Framingham's multiple-risk-factor assessment equation, a function assessing the risk of developing coronary heart disease on the basis of the presence and the level of major CV risk factors [25]. As shown in Figure 2, urinary 8-epi-PGF $2 \alpha$ did not correlate with risk level in untreated or treated subjects.

We therefore analyzed more closely factors possibly associated with lipid peroxidation in our sample, which is rather heterogeneous but is fairly representative of a population with major risk factors for cardiovascular diseases.

\section{Factors Associated with Lipid Peroxidation in Subjects at CV Risk \\ Smoking}

Multiple regression analysis of the whole group of 144 subjects showed cigarette smoking was the only strong determinant of excessive lipid peroxidation $(\beta=0.46$; $\mathrm{p}<$ 0.0001 , Table 3 ). Urinary excretion of 8 -epi- PGF $_{2 \alpha}$ was higher in smokers ( $\mathrm{n}=24 ; 14 \pm 6$ cigarettes daily) than nonsmokers $(\mathrm{n}=120)[185(91-561)$ vs $138(67-326)$ $\mathrm{pg} / \mathrm{mg}$ creatinine; $\mathrm{p}=0.003]$. Vitamin $\mathrm{E}$ did not significantly reduce levels of 8-epi-PGF $2 \alpha$ in smoking PPP participants [179 (91-498) vs 199 (138-561) pg/mg creatinine; $\mathrm{p}=0.44 ; \mathrm{n}=15$ and 9 , respectively $]$.

\section{Other factors}

The presence of smoking, a strong determinant of lipid peroxidation, very likely hampered the detection of other clinically important variables possibly associated with urinary 8-epi-PGF ${ }_{2 \alpha}$ in our initial sample. We therefore investigated the relationship between these variables and 8epi-PGF $2 \alpha$ levels in the 120 nonsmokers.

\section{Systolic blood pressure}

Lipid peroxidation appeared to be related to systolic blood pressure in nonsmokers $(\beta=0.26 ; \mathrm{p}=0.02$, Table $3)$. To confirm this in a less heterogeneous sample, we analyzed a subgroup of subjects who had hypertension as the only risk factor $(n=45)$. All except one were under antihypertensive treatment, with mean \pm SD systolic and diastolic blood pressure $145 \pm 16$ (range 107-187) and 87 \pm 8 (range 64-105) $\mathrm{mm} \mathrm{Hg}$, respectively. In this subgroup, the correlation between systolic blood pressure 


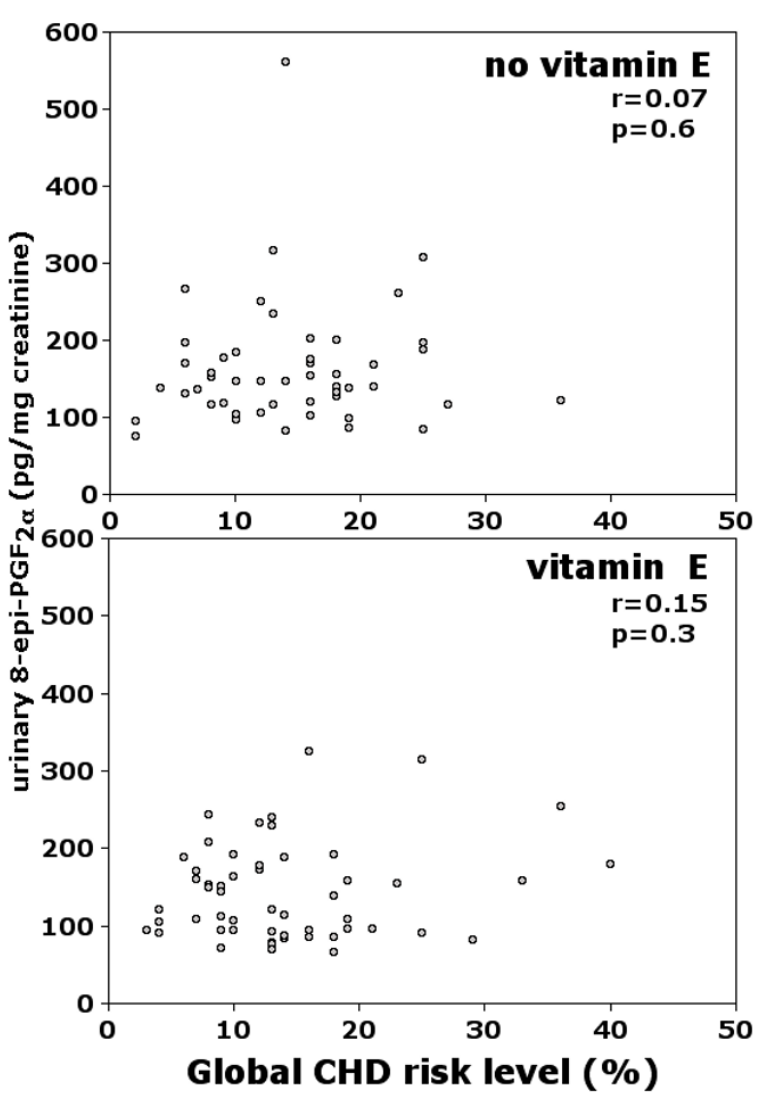

Figure 2

Correlation between global CV risk level and urinary excretion of 8-epi-PGF $2 \alpha$ in PPP participants without (upper panel) or with (lower panel) vitamin E supplementation. Risk levels, calculated according to Framingham's multiple-risk-factor assessment equation, represent coronary heart disease (CHD) individual risk over the next ten years [25].

and urinary excretion of 8-epi-PGF $2 \alpha$ was highly significant $(\mathrm{r}=0.50, \mathrm{p}=0.0005$. Figure 3$)$, and subjects with systolic blood pressure $\geq 140 \mathrm{~mm} \mathrm{Hg}$ had higher excretion of 8-epi-PGF $2 \alpha$ than those with $<140 \mathrm{~mm} \mathrm{Hg}$ [151 (140187) vs 127 (107-139) pg/mg creatinine, $\mathrm{n}=27$ and 18 , respectively, $\mathrm{p}=0.004]$. Vitamin E did not significantly affect 8-epi-PGF $2 \alpha$ excretion [109 (67-240) vs 138 (76266) $\mathrm{pg} / \mathrm{mg}$ creatinine in 21 treated and 24 untreated hypertensive subjects; $\mathrm{p}=0.19]$.

\section{Hyperglycemia}

In nonsmoking participants, blood glucose measured at the time of urine collection (mean \pm SD: $108 \pm 24 \mathrm{mg} / \mathrm{dL}$, $\mathrm{n}=94$ ) did not appear to be related to lipid peroxidation, based on multiple regression analysis $(\beta=0.17, \mathrm{p}=0.11$. Table 3). However, subjects with blood glucose $\geq 140 \mathrm{mg} /$ $\mathrm{dL}$ had higher excretion of 8-epi-PGF $2 \alpha$ than those with $<140 \mathrm{mg} / \mathrm{dL}$ [180 (121-326) vs 140 (70-266), $\mathrm{n}=10$ and

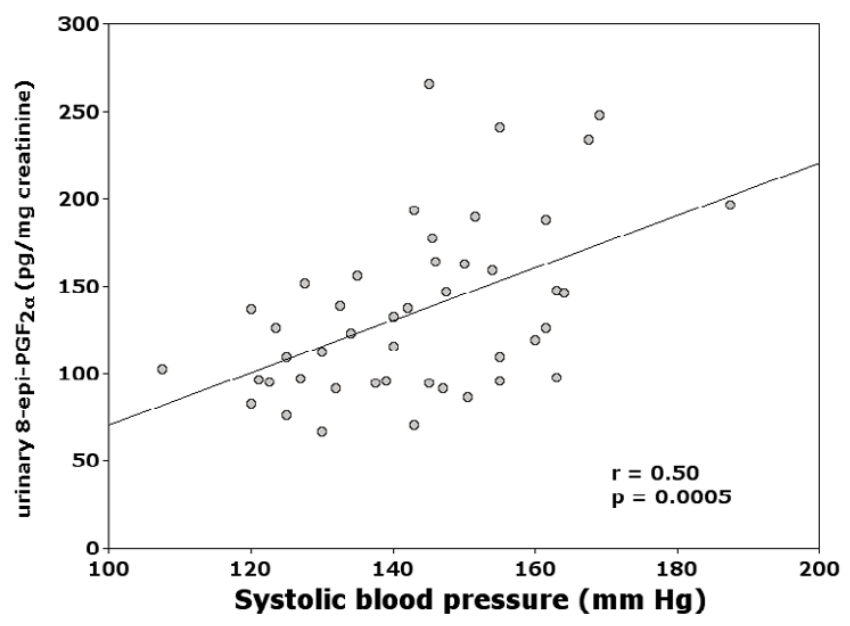

Figure 3

Correlation between systolic blood pressure and urinary excretion of 8-epi-PGF $2 \alpha$ in 45 PPP participants with hypertension as the only risk factor.

84 , respectively, $\mathrm{p}=0.009)$ ], likely because only high blood glucose levels may be associated with excessive lipid peroxidation.

\section{Other factors}

In nonsmoking PPP participants, blood cholesterol at the time of urine collection (mean \pm SD: $231 \pm 40 \mathrm{mg} / \mathrm{dL}$, range 144-351) was not significantly associated with lipid peroxidation (Table 3). Aspirin administration $(\mathrm{n}=72)$ did not affect urinary excretion of 8 -epi-PGF $2 \alpha$ (Table 3), as already reported $[14,26]$. We found no evidence (Table 3 ) of increased lipid peroxidation in relation to age, sex or obesity.

\section{Discussion}

Long-term supplementation with vitamin E-at a dose largely exceeding that of a vitamin E-rich diet $(300 \mathrm{mg} /$ day)-did not substantially reduce lipid peroxidation in people with one or more major cardiovascular risk factors. This may help explain why vitamin E was not effective for CVD prevention in the PPP study. As opposed to other studies showing an antioxidant effect of vitamin $E$ in small, uncontrolled subgroups of patients, our observations were obtained in a sample of subjects that more realistically represent a population with cardiovascular risk factors. In fact, as usually occurs in clinical practice, most candidates for cardiovascular prevention are treated-although not necessarily controlled-for their modifiable risk factors. The lack of antioxidant effect in our sample may be explained by the rather surprising finding that lipid peroxidation was normal in a large proportion of these subjects. 
We investigated whether oxidative stress was increased in high-risk subjects, given that this category could, in principle, be more sensitive to antioxidant therapy. However, we found no evidence of a correlation between $\mathrm{CV}$ risk score and urinary excretion of 8 -epi-PGF $2 \alpha$ in untreated subjects, suggesting that lipid peroxidation was not associated with their global CV risk. Although, on average, lipid peroxidation was normal in our population, it was clearly increased in relation to extreme conditions reportedly associated with oxidative stress. Lipid peroxidation was, in fact, significantly higher in smokers, in agreement with consistent evidence of elevated oxidative stress in cigarette smokers, mostly obtained using 8-epi-PGF $2 \alpha$ and/ or other $F_{2}$-isoprostanes as biomarkers $[21,22,27]$. We also confirmed previous observations that excessive lipid peroxidation in smokers cannot be reduced by vitamin $\mathrm{E}$ $[22,23]$.

A secondary, but original finding of this study is the direct relationship between urinary excretion of an $\mathrm{F}_{2}$-isoprostane and systolic blood pressure in treated hypertensive patients with different degrees of blood pressure control. Whether this relationship also exists in untreated hypertensive patients should be investigated. An association between oxidative stress and arterial hypertension has been suggested by several clinical and experimental studies [28-32]. The hypothesis that free radical-mediated mechanisms may play a role in the pathophysiology of hypertension has recently gained support from observations that antioxidants lower blood pressure in hypertensive patients [30,33-36]. However, vitamin $\mathrm{E}$ in particular does not seem effective [37], possibly because it was not antioxidant in these circumstances.

As to other factors reportedly related to in vivo lipid peroxidation, our findings agree with previous evidence. In particular, we confirmed that enhanced urinary excretion of 8-epi-PGF $2 \alpha$ is associated with impaired glycemic control in diabetic patients [17]. We did not find a correlation between urinary excretion of 8-epi-PGF $2 \alpha$ and blood cholesterol, which, on average, was slightly elevated in our sample. Such a correlation was, in fact, found in subjects with homozygote familial hypercholesterolemia and in subjects with very high blood cholesterol, but not in those with normal cholesterol levels [24].

\section{Conclusions}

Prolonged supplementation with 300 lU/day vitamin E did not reduce lipid peroxidation in subjects with one or more major cardiovascular risk factors. On average, however, lipid peroxidation was near-normal in this population. These data may help explain the overall lack of benefit of vitamin $\mathrm{E}$ in recent cardiovascular prevention trials [6-8]. They also suggest the need to reassess whether lipid peroxidation is indeed an epidemiologically relevant determinant of cardiovascular diseases and, consequently, to reconsider the utility of antioxidants as a general preventive measure.

\section{Competing Interests}

None declared.

\section{Collaborative Group}

Participating physicians: Marina Bosisio Pioltelli (general practitioner, Monza), Alberto Capra (Ospedale Civile, Voghera), Mario Cristofari (Ospedale di Desio), Gaetana Palumbo (Ospedale S. Carlo Borromeo, Milano) and Susanna Rossi (Ospedale di Rovereto)

Coordinating group: Chiara Chiabrando, Fausto Avanzini, Roberto Fanelli and Maria Carla Roncaglioni (Istituto Mario Negri, Milano)

\section{Acknowledgements}

Claudia Rivalta was supported by the Fondazione "Angela and Angelo Valenti."

\section{References}

I. Diaz MN, Frei B, Vita JA, Keaney JF Jr: Antioxidants and atherosclerotic heart disease. $N$ Engl J Med 1997, 337:408-416

2. Jialal I, Fuller C], Huet BA: The effect of alpha-tocopherol supplementation on LDL oxidation. A dose-response study. Arterioscler Thromb Vasc Biol 1995, 15:190-198

3. Marchioli R: Antioxidant vitamins and prevention of cardiovascular disease: laboratory, epidemiological and clinical trial data. Pharmacol Res 1999, 40:227-238

4. Pratico D, Tangirala RK, Rader DJ, Rokach J, FitzGerald GA: Vitamin $E$ suppresses isoprostane generation in vivo and reduces atherosclerosis in ApoE-deficient mice. Nat Med 1998, 4:1 I891192

5. Steinberg $D$ : Is there a potential therapeutic role for vitamin E or other antioxidants in atherosclerosis? Curr Opin Lipidol 2000, I I:603-607

6. Gruppo Italiano per lo Studio della Sopravvivenza nell'Infarto miocardico: Dietary supplementation with $n-3$ polyunsaturated fatty acids and vitamin $E$ after myocardial infarction: results of the GISSI-Prevenzione trial. Lancet I999, 354:447-455

7. Yusuf S, Dagenais G, Pogue J, Bosch J, Sleight P: Vitamin E supplementation and cardiovascular events in high-risk patients. The Heart Outcomes Prevention Evaluation Study Investigators. N Eng/ J Med 2000, 342:154-160

8. Collaborative Group of the Primary Prevention Project: Low-dose aspirin and vitamin $E$ in people at cardiovascular risk: a randomised trial in general practice. Lancet 2001, 357:89-95

9. Witztum JL: To E or not to E-how do we tell? Circulation 1998 , 98:2785-2787

10. Halliwell B: The antioxidant paradox. Lancet 2000, 355: I I79-I I 80

II. Hooper L, Ness AR, Smith GD: Antioxidant strategy for cardiovascular diseases. Lancet 200I, 357:1705-1706

12. Roncaglioni MC, Tombesi M, Chiabrando C, Bertele' V, Tognoni G: Antioxidant strategy for cardiovascular diseases. Lancet 200I, 357:1706

13. Meagher EA, FitzGerald GA: Indices of lipid peroxidation in vivo: strengths and limitations. Free Radic Biol Med 2000, 28: I 745-I 750

14. Delanty N, Reilly M, Pratico D, FitzGerald DJ, Lawson JA, FitzGerald GA: 8-Epi PGF $2 \alpha$ : specific analysis of an isoeicosanoid as an index of oxidant stress in vivo. BrJ Clin Pharmacol 1996, 42:15-19

15. Patrono C, FitzGerald GA: Isoprostanes: potential markers of oxidant stress in atherothrombotic disease. Arterioscler Thromb Vasc Biol 1997, 17:2309-23I5

16. Pratico D, Lawson JA, Rokach J, FitzGerald GA: The isoprostanes in biology and medicine. Trends Endocrinol Metab 200I, I 2:243247 
17. Davi G, Ciabattoni G, Consoli A, Mezzetti A, Faico A, Santarone S, Pennese E, Vitacolonna E, Bucciarelli T, Costantini F, Capani F, Patrono $C$ : In vivo formation of 8-iso-prostaglandin $F_{2}$ and platelet activation in diabetes mellitus: effects of improved metabolic control and vitamin E supplementation. Circulation 1999, 99:224-229

18. Davi G, Alessandrini P, Mezzetti A, Minotti G, Bucciarelli T, Costantini F, Cipollone F, Bon GB, Ciabattoni G, Patrono C: In vivo formation of 8-Epi-prostaglandin $\mathbf{F}_{2 \alpha}$ is increased in hypercholesterolemia. Arterioscler Thromb Vasc Biol 1997, 17:3230-3235

19. Ciabattoni G, Davi G, Collura M, lapichino L, Pardo F, Ganci A, Romagnoli R, Maclouf J, Patrono C: In vivo lipid peroxidation and platelet activation in cystic fibrosis. Am J Respir Crit Care Med 2000, 162:|195-|20|

20. Meagher EA, Barry OP, Lawson JA, Rokach J, FitzGerald GA: Effects of vitamin $E$ on lipid peroxidation in healthy persons. JAMA 200I, 285: II78-II82

21. Bachi A, Zuccato E, Baraldi M, Fanelli R, Chiabrando C: Measurement of urinary 8-Epiprostaglandin $F_{2 \alpha}$, a novel index of lipid peroxidation in vivo, by immunoaffinity extraction/gas chromatography-mass spectrometry. Basal levels in smokers and nonsmokers. Free Radic Biol Med 1996, 20:619-624

22. Reilly M, Delanty N, Lawson JA, FitzGerald GA: Modulation of oxidant stress in vivo in chronic cigarette smokers. Circulation 1996, 94:19-25

23. Patrignani P, Panara MR, Tacconelli S, Seta F, Bucciarelli T, Ciabattoni G, Alessandrini P, Mezzetti A, Santini G, Sciulli MG, Cipollone F, Davi $G$, Gallina $P$, Bon $G B$, Patrono C: Effects of vitamin E supplementation on $F_{2}$-isoprostane and thromboxane biosynthesis in healthy cigarette smokers. Circulation 2000, 102:539-545

24. Reilly MP, Pratico D, Delanty N, DiMinno G, Tremoli E, Rader D, Kapoor S, Rokach J, Lawson J, FitzGerald GA: Increased formation of distinct $\mathbf{F}_{2}$ isoprostanes in hypercholesterolemia. Circulation 1998, 98:2822-2828

25. Anderson KM, Wilson PW, Odell PM, Kannel WB: An updated coronary risk profile. A statement for health professionals. Circulation 1991, 83:356-362

26. Wang Z, Ciabattoni G, Creminon C, Lawson J, Fitzgerald GA, Patrono $C$, Maclouf J: Immunological characterization of urinary 8epi-prostaglandin $\mathbf{F}_{\mathbf{2} \alpha}$ excretion in man. J Pharmacol Exp Ther 1995, 275:94-100

27. Morrow JD, Frei B, Longmire AW, Gaziano JM, Lynch SM, Shyr Y, Strauss WE, Oates JA, Roberts LJ 2nd: Increase in circulating products of lipid peroxidation ( $F_{2}$-isoprostanes) in smokers. Smoking as a cause of oxidative damage. N Engl ] Med I995, 332:1198-1203

28. Russo C, Olivieri O, Girelli D, Faccini G, Zenari ML, Lombardi S, Corrocher R: Anti-oxidant status and lipid peroxidation in patients with essential hypertension. J Hypertens 1998, 16:1267|27|

29. Romero JC, Reckelhoff JF: State-of-the-Art lecture. Role of angiotensin and oxidative stress in essential hypertension. Hypertension 1999, 34:943-949

30. Schnackenberg CG, Wilcox CS: Two-week administration of tempol attenuates both hypertension and renal excretion of 8-Iso prostaglandin $\mathbf{F}_{2 \alpha}$. Hypertension 1999, 33:424-428

31 . Touyz RM: Oxidative stress and vascular damage in hypertension. Curr Hypertens Rep 2000, 2:98-105

32. Berry C, Brosnan MJ, Fennell J, Hamilton CA, Dominiczak AF: Oxidative stress and vascular damage in hypertension. Curr Opin Nephrol Hypertens 200I, 10:247-255

33. Galley HF, Thornton J, Howdle PD, Walker BE, Webster NR: Combination oral antioxidant supplementation reduces blood pressure. Clin Sci (Colch) 1997, 92:36I-365

34. Kitiyakara C, Wilcox CS: Antioxidants for hypertension. Curr Opin Nephrol Hypertens 1998, 7:531-538

35. Duffy SJ, Gokce N, Holbrook M, Huang A, Frei B, Keaney JF Jr, Vita JA: Treatment of hypertension with ascorbic acid. Lancet 1999 , 354:2048-2049

36. Ortiz MC, Manriquez MC, Romero JC, Juncos LA: Antioxidants block angiotensin II-induced increases in blood pressure and endothelin. Hypertension 200I, 38:655-659

37. Palumbo G, Avanzini F, Alli C, Roncaglioni MC, Ronchi E, Cristofari M, Capra A, Rossi S, Nosotti L, Costantini C, Cavalera C: Effects of vitamin $E$ on clinic and ambulatory blood pressure in treated hypertensive patients. Collaborative Group of the Primary
Prevention Project (PPP) - Hypertension study. Am J Hypertens 2000, 13:564-567
Publish with BioMed Central and every scientist can read your work free of charge

"BioMedcentral will be the most significant development for disseminating the results of biomedical research in our lifetime."

Paul Nurse, Director-General, Imperial Cancer Research Fund

Publish with BMC and your research papers will be:

- available free of charge to the entire biomedical community

- peer reviewed and published immediately upon acceptance

- cited in PubMed and archived on PubMed Central

- yours - you keep the copyright 